\title{
A CARNE COMO MALEFÍCIO: EFEITOS A PARTIR DO DIREITO HUMANO À ALIMENTAÇÃO ADEQUADA E DA GARANTIA DA SEGURANÇA ALIMENTAR
}

\section{LA CARNE COMO MALDICIÓN: EFECTOS DESDE EL DERECHO HUMANO A LA ALIMENTACIÓN ADECUADA Y DE LA GARANTÍA DE SEGURIDAD ALIMENTARIA}

${ }^{1}$ Bianca Pazzini

\section{RESUMO}

Versa este artigo sobre a necessidade de implementação de um efetivo direito humano à alimentação adequada. Para tanto, imperativo se mostra tratá-lo em consonância com a garantia da segurança alimentar e nutricional, que se mostra como algo muito mais complexo do que o mero direito de "não passar fome". Percebe-se, nesse contexto, que a produção e o consumo de carne animal pelos seres humanos mostram-se como prejudiciais à implementação do referido direito, por seus altíssimos custos socioambientais. É urgente a construção de uma nova forma de pensar a alimentação, de modo a torná-la mais integrada com os direitos humanos, com os direitos dos animais e com o meio ambiente.

Palavras-chave: Direito à alimentação adequada, Segurança alimentar e nutricional, Produção e consumo de carne

\section{RESUMEN}

Versa este artículo sobre la necesidad de aplicar un efectivo derecho humano a una alimentación adecuada. Por lo tanto, se muestra imprescindible tratarlo de acuerdo con la garantía de la seguridad alimentaria y nutricional, lo que demuestra lo mucho más complejo que el simple derecho a "no pasar hambre". Se entiende, en este contexto, que la producción y el consumo de carne de animales por los seres humanos aparecen como perjudiciales para la aplicación de este derecho, por sus altos costos ambientales y sociales. Es urgente construir una nueva forma de pensar la alimentación, con el fin de hacerla más integrada con los derechos humanos, los derechos de los animales y el medio ambiente.

Palabras-claves: Derecho a una alimentación adecuada, Seguridad alimentaria y nutricional, La producción y el consumo de carne

\footnotetext{
${ }^{1}$ Mestranda em Direito e Justiça Socia pela Universidade Federal do Rio Grande - FURG, Rio Grande do Sul (Brasil). E-mail: biancapazzini@gmail.com
} 


\section{INTRODUÇÃO}

Muito embora ainda tratado como algo de vital importância para a manutenção orgânica do ser humano, o consumo de carne apresenta uma série de impactos negativos sobre o Planeta Terra e sobre os seres humanos vistos em sua individualidade.

Especificamente sob a perspectiva da segurança alimentar e nutricional (SAN) e de um direito humano à alimentação adequada (DHAA), apresenta-se como problemática a necessidade de apurar quais são os efeitos negativos da produção e consumo de carne (e, diametralmente, dos outros produtos de origem animal), alertando para a necessidade de construção de alternativas viáveis à promoção dos direitos humanos.

Objetiva-se com este trabalho fornecer elementos para a construção de uma nova forma de pensar a segurança alimentar, de modo a torná-la mais integrada com os direitos humanos, com os direitos animais e com o meio ambiente.

Como metodologia geral de trabalho optou-se pelo método hipotético-dedutivo, e quanto aos procedimentos técnicos, trata-se de pesquisa essencialmente bibliográfica e documental, realizada através da leitura e fichamento crítico de livros, artigos científicos e outros documentos (incluindo notícias, relatórios de órgãos de estatística etc).

Ao tratar de direitos exclusivamente humanos, a pesquisa acaba ocorrendo pela perspectiva antropocêntrica. No entanto, saliente-se também uma posição de respeito e observância aos direitos animais, que apenas não são traduzidos em primeiro plano, mas igualmente defendidos.

Por fim, cabe advertir que o tema desvela grandes desdobramentos, pelo que coube tratar apenas seus aspectos mais relevantes ante tamanha complexidade.

\section{O DIREITO À ALIMENTAÇÃO ADEQUADA NO CONTEXTO HODIERNO: PANORAMA GERAL}

A questão que se refere à alimentação é cada vez mais um problema estatal. Tanto no que se refere à necessidade de prover alimentos na quantia necessária a todos os seus cidadãos (por meio de políticas públicas de combate à pobreza extrema, à fome e à desnutrição), tanto no que diz à qualidade da alimentação (para promover uma alimentação rica em nutrientes e para fiscalizar as condições de plantio, produção e distribuição dos alimentos - a fim de que não ofereçam riscos à saúde coletiva). 
Esse contexto decorre da existência de um novo papel do Estado, que agora se mostra responsável pela realização positiva do bem comum, para além do laissez-faire, laissez passer liberal previsto por Quesnay no século XVIII. A mera não-intervenção do Estado nas questões privadas, que antes simbolizava "liberdade", agora mostra-se como violação à necessidade de promoção da igualdade. É necessária uma atuação positiva para encaminhamento das demandas sociais, com intervenção em todos os assuntos afetos ao bemestar da população.

De acordo com Elisabete Maniglia,

O Estado contemporâneo volta-se para a defesa dos direitos individuais, consagrados em suas constituições, insere como direitos fundamentais os direitos sociais e/ou coletivos e, para assegurar a efetiva realização desses direitos, estabelece a sua disciplina e a sua intervenção nos domínios econômico e social (MANIGLIA, 2009, p. 118).

Ocorre que, não obstante a existência indiscutível desse poder-dever estatal, é fato que a quase totalidade dos direitos fundamentais ainda não se veem efetivados, especialmente em relação às camadas mais pobres - vulneráveis e invisíveis - da população.

Uma das maiores mazelas é a questão que envolve o direito à alimentação adequada - positivado recentemente no art. $6^{\circ}$ da Constituição Federal por meio da EC n ${ }^{\circ} 64 / 2010$-, que se refere a algo muito mais complexo que a mera subsistência orgânica do ser humano ou a um mero direito de não morrer de fome.

Os mais recentes instrumentos jurídicos de direito internacional foram além deste entendimento restrito, reconhecendo que o direito à alimentação adequada deve ser compreendido de forma mais abrangente, contemplando também o acesso aos gêneros alimentícios - ou seja, que os alimentos possam estar física e economicamente acessíveis a todos -, bem como a quantidade e a qualidade necessárias para suprir as necessidades nutricionais do ser humano, permitindo seu pleno desenvolvimento e a manutenção de sua saúde (GRAFF, 2013, p. 11-2).

Para que se veja concretizado um notório direito à alimentação adequada, é especialmente necessário que: (a) haja produção de alimentos em quantidade suficiente para abranger toda a população de determinado território e a mínima viabilidade em termos de oferta e demanda -, o que pode ser nominado como condições físicas ou econômicas; (b) consolidemse políticas sociais e econômicas de combate à extrema pobreza (sendo esta a grande responsável pela incidência de fome e desnutrição no mundo), ao que podemos chamar condições sociais; (c) exista conscientização de uma necessária "educação alimentar" apta a ensinar que não basta consumir alimentos em quantidade suficiente, mas que é imprescindível 
atentar aos valores nutricionais dos alimentos, evitando doenças cardiovasculares, anemia, obesidade e tantas outras mazelas decorrentes da alimentação deficitária em nutrientes; (d) sejam desenvolvidos e ofertados à população produtos livres de componentes nocivos ao organismo humano (tóxicos, cancerígenos etc) ou que respeitem a sustentabilidade ambiental.

Os dois primeiros aspectos desse direito à alimentação adequada - itens ' $a$ ' e ' $b$ ' pelo que se entende, constituiriam o que se pode chamar de um "direito formal à alimentação", pois se referem a um mero acesso (socioeconômico) a produtos alimentícios. Por outro lado, poderíamos dizer que os dois últimos itens - ' $c$ ' e 'd' - mais refinados do ponto de vista teórico (e prático), constituiriam um "direito material à alimentação adequada", pois consagrariam uma verdadeira alimentação de qualidade, apta à manutenção de uma vida humana saudável.

Nesse sentido,

[...] estabelece-se o direito à alimentação que é muito mais do que comer para sobreviver. Alimentar-se é um ato que projeta mais que sobrevivência, é uma permissão a uma vida saudável e ativa, dentro dos padrões culturais de cada país, com qualidade que propicie nutrição e prazer, e os produtos alimentícios devem ser inspecionados por órgãos responsáveis, que devem zelar continuamente por sua oferta e sua segurança às populações (MANIGLIA, 2009, p. 123).

A autora, embora consiga vislumbrar esse aspecto mais refinado e profundo relativo ao direito, não esquece que o acesso à alimentação (referido neste trabalho como direito formal à alimentação) está extremamente ligado à questão da pobreza, que "é a inimiga número um da sustentabilidade alimentar" (MANIGLIA, 2009, p. 124). É a pobreza não combatida que gera a fome e inviabiliza a aplicação do mais básico e formal direito à alimentação - tornando o direito material à alimentação uma utopia. Como problemática adicional, tem-se que essa pobreza origina-se, geralmente, de um sem número de outros problemas sociais de difícil resolução, como, por exemplo, desigualdade social, desperdício em todos os níveis de produção e consumo, concentração de rendas, exploração dos mais fracos e pobres, guerras, corrupção, aumento das doenças, exploração não sustentável dos recursos naturais, ganância dos ricos, falta de solidariedade etc.

Segundo estimativas da Organização das Nações Unidas para Agricultura e Alimentação - FAO, no período 2010-2012, o número de pessoas subnutridas no mundo atingiu 870 milhões, o que representa $12,5 \%$ da população mundial, ou uma em cada oito pessoas. Grande parte desse percentual - cerca de 852 milhões -, vive em países em desenvolvimento, onde se estima que a prevalência da subnutrição atinja $14,9 \%$ da população (GRAFF, 2013, p. 16). 
No Brasil os dados não são menos assustadores, e demonstram requintes de crueldade no que diz à caracterização da fome atrelada a aspectos discriminatórios. Aqui a fome é notadamente destinada àqueles grupos historicamente segregados. Como se vê nas estatísticas a seguir:

Os mais atingidos pela fome, em proporcionalidade, são os negros: $52,3 \%$ deles residem em domicílios sob o risco de conviver com a fome, enquanto $28 \%$ dos brancos são atingidos pelo problema. Tal desigualdade afeta também as mulheres e a população mais jovem. Nos lares chefiados por mulheres, há uma insegurança alimentar na faixa de $22,9 \%$ contra 17,3\% naqueles coordenados por homens. A mesma pesquisa demonstra nitidamente que a fome deriva da falta de rendimentos, de emprego, de condições estruturais (MANIGLIA, 2010, p. 151).

É nítida a estigmatização das minorias - sejam elas de cunho racial, sexual etc. Necessariamente os homens brancos (na média, pois sempre há casos discrepantes e exceções) viverão melhor que mulheres e negros, ainda subalternizados e "invisíveis" ante as elites. O “outro" (DUSSEL, 1990), alvo de preconceitos e discriminações por ser minoria, é também condenado à fome.

Assim, a despeito da existência desses dados alarmantes, a alimentação é direito humano básico, de obrigatória observância pelo Estado. E, felizmente, há um esforço no sentido de mudar tal cenário. Arrolado como direito social na Constituição Federal, o direito humano à alimentação adequada é um dos direitos que demandam aplicação com atuação constante e progressiva, não sendo possível a sua implementação sem a existência de um mínimo de recursos econômicos, de disponibilidade política, de aparato técnico e de cooperação econômica internacional: é inviável sua implementação sem a representação efetiva de prioridade na agenda política nacional.

Não obstante isso, quando "os Estados se voltam para as políticas de erradicação da fome, são muitos os que interpretam essa postura como política de assistencialismo ou benesse dos órgãos públicos, inclusive alegando o desatino do uso das verbas públicas" (MANIGLIA, 2009, p. 128). A indiferença e o preconceito se manifestam inclusive para impedir que o Estado tome providências no sentido de erradicar a fome, e flagrantemente mostram-se como posturas errôneas.

Programas de transferência de renda como o Bolsa Família, por exemplo, apresentam bons resultados no combate à fome e consequente efetivação de um direito à alimentação (ainda que em seu aspecto mais básico, é verdade), e dados recentes apontam que o referido programa reduziu a extrema pobreza em $28 \%$ em seus 10 anos de implantação. Os 
dados absolutos mostram ainda que mais de 36 milhões de pessoas saíram da faixa de miséria (IPEA, 2013).

Sem embargo, tais políticas - eminentemente assistenciais - de transferência de renda devem ocorrer por um curto período, apenas enquanto começam a fazer efeitos as políticas paralelas e concomitantes de investimento em capital humano de longo prazo. Além do mais, elas sozinhas não resolvem o problema, remanescendo focos de fome e de miséria em todo o território nacional. Fato é que

A pobreza gera a desnutrição, que pode ser entendida como a consequência de um processo contínuo de carência alimentar: ingerindo menos calorias (energia) do que o necessário para o desenvolvimento adequado, a pessoa não se desenvolve. Mas não é só. Hoje, muitas pessoas no mundo sofrem de outros problemas decorrentes da má alimentação. Embora tenham acesso à alimentação suficiente, passam por problemas de obesidade e outras doenças decorrentes das carências nutricionais a uma vida saudável (MANIGLIA, 2009, p. 124).

É por isso que o direito à alimentação não pode se reduzir à mera oferta de alimentos, mas compreender um rol muito mais amplo de necessidades que passam inclusive por iniciativas ligadas à saúde e educação. Nesse contexto surge a importância do direito à alimentação como fenômeno complexo, que traz em seu bojo um aspecto instrumental de suma importância, qual seja, a segurança alimentar.

\section{SEGURANÇA ALIMENTAR E NUTRICIONAL (SAN) E DIREITO HUMANO À ALIMENTAÇÃO ADEQUADA (DHAA): EVOLUÇÃO, CARACTERES, SEMELHANÇAS E DIFERENÇAS}

Partindo-se da proposição que a segurança alimentar é um aspecto de altíssima relevância junto do direito humano à alimentação adequada, há que se reconhecê-la como item de elevada relevância social.

Sua importância surge no contexto da I Guerra Mundial, ante a incerteza que os países tinham acerca da suficiência de produzir e distribuir os alimentos suficientes à subsistência de sua população - ante a possibilidade de boicotes políticos ou militares. A segurança alimentar era inicialmente compreendida como uma política de armazenamento e oferta de alimentos, e não como um direito humano. Tinha um viés estatal eminentemente estratégico, e não social - o estoque era um fim em si mesmo, e não um meio de atender necessidades humanas. Posteriormente é que se passou a perceber que os alimentos não eram insuficientes, mas mal distribuídos. 
Sob essa concepção, um primeiro grande marco mundial pelo combate à fome ocorreu em 1996, em Roma. Lá 185 países e a Comunidade Europeia reuniram-se para debater tal assunto, comprometendo-se a erradicar a fome de todos os países do globo. Tal compromisso - não cumprido - deu origem à 'Declaração de Roma sobre Segurança Alimentar'. Trazia como finalidade maior "atingir uma segurança alimentar para todos e a realização de um esforço permanente para erradicar a fome em todos os países, com o objectivo imediato de reduzir, até metade do seu nível actual, o número de pessoas subalimentas até, ao mais tardar, o ano 2015” (FAO, 1996).

Antes disso, em 1983, a Organização de Alimentação e Agricultura das Nações Unidas (FAO) apresentou um conceito tripartido de segurança alimentar, atinente aos objetivos: (a) oferta adequada de alimentos; (b) estabilidade da oferta e dos mercados de alimentos; e (c) segurança no acesso aos alimentos ofertados (HIRAI; ANJOS, 2007, p. 339).

A partir da década de 90 do século 20, o conceito evoluiu, englobando cinco aspectos, quais sejam: (a) noções de alimento seguro; (b) qualidade do alimento; (c) balanceamento da dieta; (d) informação sobre os alimentos; e (e) opções de hábitos alimentares em modos de vida (HIRAI; ANJOS, 2007, p. 340).

Essa sucessão histórica demonstra uma evolução de um conceito de "segurança alimentar" (referente ao acesso a alimentação e nutrição adequadas, com plenas condições orgânicas ou fisiológicas de aproveitar os alimentos ingeridos) para uma necessária "segurança alimentar e nutricional" (que é um conceito mais amplo e abrange, além do já referido, aspectos tais como sustentabilidade - econômica e ambiental -, saúde, condições ambientais etc).

No ordenamento jurídico pátrio, a Lei $\mathrm{n}^{\circ}$ 11.346, de 15 de setembro de 2006, veio com a finalidade de tratar da segurança alimentar e nutricional, e o faz com boa técnica legislativa.

Os incisos do artigo $4^{\circ}$ da referida norma, por sua vez, revelam um tratamento holístico à segurança alimentar e nutricional, de modo a abranger vários elementos, dentre os quais: (a) "ampliação das condições de acesso aos alimentos por meio da produção [...]"; (b) "conservação da biodiversidade e a utilização sustentável dos recursos"; (c) "promoção da saúde, da nutrição e da alimentação da população, incluindo-se grupos populacionais específicos e populações em situação de vulnerabilidade social"; (d) "garantia da qualidade biológica, sanitária, nutricional e tecnológica dos alimentos [...]”; (e) "produção de conhecimento e o acesso à informação"; e (f) "implementação de políticas públicas e estratégias sustentáveis e participativas de produção, comercialização e consumo de alimentos, respeitandose as múltiplas características culturais do país" (BRASIL, 2006). 
Com essa vasta base, $o$ art. $3^{\circ}$ de lei traz então um conceito de segurança alimentar, tratando-se esta da

[...] realização do direito de todos ao acesso regular e permanente a alimentos de qualidade, em quantidade suficiente, sem comprometer o acesso a outras necessidades essenciais, tendo como base práticas alimentares promotoras de saúde que respeitem a diversidade cultural e que sejam ambiental, cultural, econômica e socialmente sustentáveis (BRASIL, 2006).

Ante tais aspectos, percebe-se que a segurança alimentar e nutricional é o meio pelo qual se efetiva o direito à alimentação adequada. Tem, portanto, um caráter instrumental. Tratase do aspecto prático de exercício do direito.

Entende-se que "direito humano à alimentação adequada" e "segurança alimentar e nutricional" encaixam-se com perfeição na dicotomia "direito e garantia", respectivamente. Isso porque Uadi Lammêgo Bulos (2008, p. 231) - fazendo referência à Rui Barbosa - revela que as disposições constitucionais meramente declaratórias (que apenas prescrevem direitos já reconhecidos) são direitos, enquanto que garantias são limitadores do poder estatal, com conteúdo assecuratório de direitos.

Nesse sentido, direitos não se confundiriam com garantias fundamentais, pois os primeiros são bens e vantagens disciplinados na Constituição Federal, e imprimem existência legal aos direitos já em vigor no Estado. As garantias fundamentais, no entanto, são as ferramentas jurídicas por meio das quais tais direitos se exercem, limitando os poderes do Estado.

Canotilho, sob esta acepção, retrata que "[...] as clássicas garantias são também direitos, embora muitas vezes se salientasse nelas o caráter instrumental de protecção dos direitos. As garantias traduziam-se quer no direito dos cidadãos a exigir dos poderes públicos a protecção dos seus direitos, quer no reconhecimento de meios processuais adequados a essa finalidade" (CANOTILHO, 1998, p. 372).

Posicionamento diverso aduz que "não são nítidas, porém, as linhas divisórias entre direitos e garantias" (SILVA, 2008, p. 186), de onde se afirma que "os direitos são garantias, e as garantias são direitos" (DÓRIA, citado por SILVA, 2008, p. 181). Independente disso, a Magna Carta não deixa clara a distinção entre direitos e garantias, misturando e integrando o tratamento dado a ambos. Isso não significa, porém, que a distinção não exista, mas apenas que deixou de ser observada pelo legislador constituinte.

Ultrapassado o debate, parece acertado defender a alimentação adequada como direito - eis que inclusive prescrita expressamente no art. $6^{\circ}$ da Carta Magna - e a segurança 
alimentar e nutricional como garantia, dado seu caráter instrumental de exercício do direito. Desse modo, a alimentação adequada "é um direito humano de todos e a garantia da Segurança Alimentar e Nutricional para todos é um dever do Estado e responsabilidade da sociedade" (BURITY et. al, 2010, p. 23).

Fato é que, independente de estarmos tratando do direito ou da garantia, ambas têm a mesma nobre finalidade, apenas se manifestando de maneira diferente no mundo jurídico.

Ocorre que enfrentamos problemas de efetivação dos processos mais rudimentares da segurança alimentar - correspondente ao acesso físico e econômico à alimentação. No Brasil remanesce uma situação desesperadora, em patamares absurdos, já que em 2010 ainda tínhamos

[...] 35 milhões de pessoas com fome crônica; de cada cinco brasileiros, um passa fome; de cada três crianças, uma é desnutrida [...] grande parcela da população vivendo em condições de indigência, principalmente no meio rural. Nesse setor, $50 \%$ das pessoas vivem abaixo da linha da pobreza. Também aí se encontram os mais elevados índices de desnutrição infantil. Situação ainda mais crítica é a dos trabalhadores rurais sem terra. Estima-se que no País existam 4,8 milhões de famílias sem terra para viver e trabalhar. Há também a situação dos pequenos agricultores que, mesmo possuindo terra, não dispõem das condições mínimas necessárias para gerar o sustento de suas famílias (MANIGLIA, 2010, p. 149).

Daí se consegue extrair um círculo vicioso dos mais alarmantes, que demonstra que a pobreza gera a fome, que gera desnutrição, que gera outras doenças, que gera problemas nos serviços de saúde que, com os grandes custos do sistema de saúde impossibilitam novos investimentos em emprego e renda, que por sua vez geram mais pobreza e assim por diante.

Um outro aspecto a ser considerado diz respeito ao modo como cada país trata a questão da segurança alimentar e nutricional. Sob esta acepção, percebe-se um tratamento muito diverso se compararmos América Latina e União Europeia.

A União Europeia centrou sua preocupação nas questões agrícolas e de produção dos alimentos, com vistas à manutenção da saúde coletiva em seu território. Há uma observância holística na fiscalização dos alimentos, com vistas a combater riscos de toda ordem - ambientais, toxicológicos etc. Segundo Maniglia (2009, p. 139), a "segurança dos alimentos é uma das prioridades máximas na Europa, e sua nova abordagem é bem mais integrada, já que a rastreabilidade dos alimentos é assegurada desde a exploração agrícola até a mesa do consumidor". Quanto aos riscos, tais são profundamente estudados, valendo-se a União Europeia inclusive de aconselhamentos científicos para autorizar ou proibir qualquer produto, ingrediente, componente químico ou organismo geneticamente modificado. 
Vê-se que na União Europeia os consumidores têm facilidade de acesso às informações completas sobre os componentes dos produtos que pretendem consumir, inclusive acerca da existência de produtos de origem animal - assunto ao qual voltaremos no terceiro capítulo.

As metas da União Europeia são ambiciosas; a pedra basilar para seus programas de ações, hoje, são a questão ambiental, as alterações climáticas e o aquecimento do planeta; os habitats naturais e a vida selvagem; as questões de ambiente e saúde; os recursos naturais e a gestão de resíduos. Essas ações têm como objetivo melhorar a produção de alimentos e a saúde humana. Objetivam também preservar o patrimônio rural e diminuir ao máximo as populações urbanas (MANIGLIA, 2010, p. 146).

$\mathrm{Na}$ América Latina, por outro lado, há uma preocupação geral diversa, pois o enfoque maior está na possibilidade de acesso à alimentação, em virtude de maior incidência de fome e miséria. Ao passo que a União Europeia elabora normas para fiscalização dos alimentos a serem consumidos pela própria população - por uma questão de saúde pública -, nos países da América Latina - especialmente o Brasil - há um interesse em melhorar a qualidade dos alimentos não como um fim em si mesmo, mas para que o produto adquira a característica "tipo exportação". Tal fato revela uma perspectiva desrespeitosa à vida humana local, que visa o lucro acima de quaisquer valores. É o que explica Elisabete Maniglia (2010, p. 243-4):

[...] os alimentos para consumo da União Europeia devem estar dentro de regras $[. .$.$] que ambicionam a qualidade dos produtos, desde a origem das$ sementes até a mesa do consumidor; portanto, só se comprarão produtos agropecuários se os requisitos forem preenchidos. Assim, muita coisa tem mudado para satisfazer o comércio internacional. No entanto, no âmbito interno, a ausência de cuidados ambientais, a pobreza e a desigualdade social geram os danos irreversíveis ao meio ambiente [e à saúde humana], provocando um ciclo vicioso que empobrece o meio rural. A ânsia dos empresários em fazer crescer seus lucros derruba matas, polui águas, tira riquezas e sobrevivência dos pobres.

Carece-se da implementação de uma efetiva segurança alimentar. Para isso, a agricultura deve deixar de ser uma mera atividade econômica para atingir uma função social, a fim de que se observe a qualidade de vida dos destinatários dos alimentos produzidos, tanto no que diz à adequação do alimento propriamente dito quanto à preservação do meio ambiente.

Não obstante a inclusão do direito à alimentação na CF não torná-lo eficaz de imediato, tal fato não pode ser desprezado, por demonstrar um interesse do Estado brasileiro em provê-lo, bem como o fato de que tal direito agora se insere no princípio da proibição do retrocesso (GRAFF, 2013, p. 36). 
Além do mais, "[...] a existência de fome no Brasil não é efetivamente um problema de insuficiência de produção de alimentos. A grande limitação está, decididamente, no acesso ao alimento que, colocado no mercado, é apenas acessível a quem disponha de renda" (MANIGLIA, 2010, p. 152). Percebe-se a economia como uma grande determinante na (falta de) concretização de direitos humanos básicos.

$\mathrm{O}$ aspecto atinente à concretização de interesses econômicos é uma das problemáticas mais graves na não efetivação da segurança alimentar. Organismos geneticamente modificados (OGMs) são desenvolvidos para melhorar a produção de alimentos, expondo o ser humano a uma inimaginável gama de riscos em nome do lucro; agrotóxicos, notadamente prejudiciais à saúde e ao planeta, são vastamente utilizados a despeito dos alertas de perigo emitidos por todos os cientistas sérios do planeta.

Exemplos não faltariam para mostrar o impacto da ganância econômica sobre a concretização da segurança alimentar e nutricional, no entanto, o que mais choca é o processo de produção de produtos de origem animal. Esse segmento, por mostrar-se como o mais ameaçador ao direito humano à alimentação adequada - tanto pela segregação econômica como pela soma de outras consequências nefastas - será abordado no tópico que segue.

\section{A PRODUÇÃO E O CONSUMO DE CARNE: IMPACTOS NA SEGURANÇA ALIMENTAR}

Embora a produção (e o respectivo consumo) de carne - e outros produtos de origem animal - não sejam usualmente vistos como uma problemática ou influência na segurança alimentar e nutricional, é possível apontar tal aspecto como uma das mais relevantes fontes de impedimento na realização de um direito humano à alimentação adequada, pois as consequências dessa produção incidem em larga escala e nos mais diversos aspectos da vida humana - econômicos, sociais, ambientais, jurídicos, políticos etc.

A produção e o consumo de carne, em relação aos demais produtos de origem animal (que se revelam sob diversas formas, tais como queijos, leites, ovos, processados etc) apresentam resultados muito semelhantes em termos de impactos na segurança alimentar. Todavia, a fim de centralizar a análise no que há de mais relevante, optou-se por verificar apenas a questão que envolve a produção da carne, considerando-se esta a mais massiva e relevante em termos de efeitos.

Sendo múltiplas as decorrências desse produto na segurança alimentar e nutricional, optou-se por dividir a análise em quatro itens distintos - a despeito de estarem todos muito 
interligados -, a saber: (a) implicações na economia (pela ótica do produtor e do lobby para manutenção da indústria e do status quo); (b) impactos econômicos para o consumidor - preço elevado e seleção no consumo; (c) prejuízos ambientais e falta de sustentabilidade; (d) efeitos para a saúde humana.

\subsection{IMPLICAÇÕES NA ECONOMIA}

Pelo que já se viu ao longo deste trabalho, sabe-se que a segurança alimentar no Brasil nunca esteve desvinculada do combate à fome e a questões de luta pela democracia ou por justiças social e econômica. No entanto, a economia "é a grande determinante na realização dos direitos fundamentais básicos. Alimento, saúde, trabalho e ensino estão submetidos à ordem econômica que hoje, no contex to internacional, interliga países ricos e pobres sob o domínio do monopólio global” (MANIGLIA, 2009, p. 119).

Isso gera um conflito natural de interesses entre as populações vulneráveis e os grandes empresários (da indústria de alimentos ou não) - pois estes têm interesse em vender a maior quantidade de alimentos possível, remunerando minimamente seus empregados (o que culmina em pobreza e ausência de uma sadia qualidade de vida). Sendo estes trabalhadores uma fatia bem considerável da população, observa-se uma enorme desigualdade social, perpetuada pelo sistema capitalista.

A questão do agronegócio levanta muitas discussões no campo da ética, por seu caráter muitas vezes exploratório. Nesse sentido, há que se ter em mente que

O agronegócio não é crime, nem sabotagem aos pobres. Simplesmente, é uma atividade exercida, quase sempre, de forma monocultural, preocupando-se muito pouco com o meio ambiente, envolvendo capital estrangeiro, clamando por altos empreendimentos, monopolizando mercados, trabalhando sob pressão internacional, estando voltado para a alta tecnologia e exigindo apoio estatal diuturno. Muitas vezes, insere o trabalho escravo em seus negócios - como, há tempos, foi registrado, quem escraviza seus trabalhadores não são os proprietários mal informados, escondidos em fazendas atrasadas; ao contrário, são os empresários do agronegócio, produzindo com alta tecnologia, em fazendas de gado, café, soja e extrativismo de madeira (MANIGLIA, 2010, p. 187-8).

Trazendo para o aspecto da produção da carne em especial, a lógica de mercado é ainda mais cruel, pois, além dos aspectos acima descritos, há uma engenhosa e inescrupulosa cadeia de produção desenvolvida apenas com a finalidade de manter lucros para os “empreendedores". Referimo-nos à quantidade de alimentos empregada em seu processo de produção - para alimentar os animais - que poderiam servir de alimento direto à população, 
com um custo econômico e ambiental muito aquém do praticado hoje. A estimativa é de que metade dos grãos produzidos no mundo sejam utilizados na alimentação dos animais para consumo, enquanto cerca de 870 milhões de pessoas não têm o que comer.

De acordo com os dados divulgados no documentário “A Engrenagem” (2012) produzido pelo Instituto Nina Rosa -, a terra suficiente para produzir o equivalente a 210 quilogramas de carne bovina poderia dar lugar ao equivalente a 5 toneladas de feijão; ou 16 toneladas de trigo; ou 4 toneladas de cenoura; ou 40 toneladas de tomates; ou 13 toneladas de arroz; ou 23 toneladas de milho.

Esse fato não é divulgado porque desobedece à "lógica do Produto Interno Bruto (PIB)" e à regra da oferta e da demanda. Uma grande oferta de alimentos diminuiria o preço para o consumidor (o que de per si, em contrapartida, diminuiria a fome no mundo), impactando gravemente na economia. Isso porque o PIB - que não mede qualidade de vida - diminuiria quando diminuíssem os processos na produção de alimentos. É fato, entretanto, que tal índice gera uma falsa sensação de riqueza ao país, mas não melhora em nada as condições de vida das classes mais baixas ou sequer dos trabalhadores da indústria (que deveriam partilhar dos lucros). Resumindo, não faz sentido criar bilhões de animais e plantar uma quantia proporcional de grãos apenas para alimentar os animais que serão posteriormente abatidos para consumo.

Entende-se que os resultados econômicos não podem ser dissociados da melhoria da qualidade de vida das pessoas, especialmente as mais vulneráveis. O desenvolvimento de um “capitalismo humanista" é o mínimo ético para o desenvolvimento de uma sociedade menos predatória. No entanto, o que a indústria da carne mostra é uma grande fatia da população que não pode adquirir os produtos por ela produzidos, como se verá no tópico a seguir.

Ademais, o poderio da indústria da carne (que a cada ano bate recordes de faturamento interno e exportação) impede a livre escolha dos alimentos a serem consumidos, retirando do consumidor a possibilidade de decidir efetivamente o que comer.

\subsection{IMPACTOS ECONÔMICOS PARA O CIDADÃO}

A carne é, de longe, o produto mais caro da chamada “cesta básica”. Isso no que diz apenas ao custo econômico que gera à população (os custos ambientais serão parcialmente vislumbrados no ponto a seguir; e os custos sociais - tais como trabalho escravo, custos previdenciários e outros análogos - fugiriam à temática da segurança alimentar e nutricional, objeto do presente trabalho). 
A maioria da população entende que a carne é um produto indispensável em cada uma das refeições realizadas - por razões culturais, por falta de informação e, principalmente, por lobby da indústria da carne junto à grande mídia. Em função disso, até as pessoas em extrema pobreza veem na carne um objeto de consumo de primeira ordem, deixando de comprar outros itens alimentícios a fim de garantir um bife, um pedaço de frango ou um pouco de "guisado" (como costumeiramente é chamada a carne moída no Rio Grande do Sul).

A carne agrega o "status de consumidor" aos seus adquirentes e segrega os que não podem pagar por ela - ou se é cidadão-consumidor ou se é nada.

Apenas para fins de ilustração do que aqui se tem argumentado, utilizemo-nos dos valores dos produtos disponíveis nos "supermercados" para comparação: com o valor equivalente à compra de 1 quilograma de carne bovina de razoável qualidade - em torno de $\mathrm{R} \$ 15,00$ (quinze reais), é possível comprar: 1 quilograma de feijão, 1 quilograma de arroz, 1 ramo de alface, 1 quilograma de tomate, 1 quilograma de batata e 2 ou 3 unidades grandes de cenoura. Tal comparativo, apesar de sua simplicidade, demonstra a discrepância entre os custos de aquisição de produtos de origem animal e vegetal - sendo que esta última proporcionaria uma dieta muito mais rica em nutrientes, satisfazendo com maior plenitude o direito humano à alimentação adequada.

Baseando-se nesses dados, pergunta-se: em vez de alimentar animais para que estes sirvam de alimento aos privilegiados que podem pagar, porque não fazer com que os alimentos vegetais sirvam diretamente à população (diminuindo drasticamente a fome no mundo)?

\subsection{IMPACTOS AMBIENTAIS}

A verificação dos impactos ambientais mostra-se como de extrema relevância em matéria de segurança alimentar, em virtude dessa visão integrada com o meio ambiente, necessária a uma boa realização de um direito humano à alimentação adequada. Isso porque a falta de um meio ambiente ecologicamente equilibrado compromete o acesso à alimentação e a vida humana. Nessa toada, percebe-se a criação de animais para produção de carne como uma das ações mais degradantes ao meio ambiente, desfazendo quaisquer outros esforços no sentido de vivermos em uma sociedade sustentável.

Prova disso é o fato de a Organização das Nações Unidas, em um relatório do ano de 2010, ter recomendado as dietas vegetarianas e veganas (esta última livre de quaisquer produtos de origem animal) como meio de extrema importância para salvar o planeta da estafa ambiental, considerando os impactos que a produção pecuária causa ao meio ambiente. 
Ademais, o relatório da Organização das Nações Unidas para a Alimentação e Agricultura (FAO) indica que a atual produção de carne contribui com um percentual entre 14\% e $22 \%$ do total de gases do efeito estufa produzidos anualmente no mundo - perdendo apenas para a produção de energia, mas ganhando com larga vantagem de todos as outras formas de produção de efeito estufa, incluindo as advindas de todas as formas de transporte juntas. Isso tudo significa que produzir cerca de 200 gramas de hambúrguer para um lanche libera tanto gás de efeito estufa na atmosfera quanto dirigir um carro de $1.360 \mathrm{~kg}$ por aproximadamente $16 \mathrm{~km}$ (SCIENTIFIC AMERICAN BRASIL, [s.d.]).

Entretanto, esse não é o único impacto ambiental que a produção de carne gera. Além da emissão de gases de efeito estufa, há ainda os problemas referentes ao desmatamento, à excessiva emissão de dejetos decorrentes da criação dos animais (especialmente das fezes, além daqueles decorrentes do abate) e ao exorbitante consumo de água.

Sobre a questão do desmatamento, observa-se que a chamada "pecuária de corte" pode gerar a destruição de ecossistemas ambientais. Isso porque "o esgotamento ou a baixa produtividade de determinadas áreas incentiva a expandir seus domínios sobre biomas naturais, destruindo os habitats naturais de várias espécies" (CEPEA, 2008, p. 3). Estima-se que 91\% da área desmatada da Amazônia decorra dessa atividade (A ENGRENAGEM, 2012).

Não bastasse a destruição de biomas inteiros, fato é que a atividade pecuária tende a desgastar o solo de maneira a retirar dele toda a fertilidade, em função do baixo investimento na manutenção de pastagens, o que pode provocar compactação e erosão do solo (CEPEA, 2008, p. 4).

Problema tão sério quanto o desmatamento é o relativo ao alto volume de dejetos produzidos pelos animais, que, criados em larga escala, poluem o solo, os lençóis freáticos, os rios e o mar - além dos gases que emitem -, poluindo o meio ambiente de maneira avassaladora.

Outro item preocupante é a pesca predatória que avassala a vida marítima. Estimase que para quilograma de camarão pescado, podem ser simplesmente jogados fora vinte quilogramas de outros animais pescados "sem querer", que vêm junto nas redes (A ENGRENAGEM, 2012).

No que se refere à questão da água, tem-se o seguinte: para a produção de um quilograma (1kg) de laranja, são necessários 560 litros de água; para a mesma quantia de banana, 790 litros de água. No entanto, para a produção de $1 \mathrm{~kg}$ de carne de suína e $1 \mathrm{~kg}$ de carne bovina são necessários, 5.988 e 15.400 litros de água, respectivamente (A ENGRENAGEM, 
2012). Tal cálculo demonstra uma exorbitância de dispêndio de recursos naturais que não mais se justifica (por todos os elementos tratados aqui neste capítulo).

Ainda sobre o recurso (escasso) da água, soma-se à poluição decorrente dos dejetos a "carga de nutrientes (nitrogênio, fósforo, potássio do esterco), hormônios, metais pesados e patógenos carregados para o leito dos rios pela lixiviação do solo” (CEPEA, 2008, p. 4).

No meio rural, na ânsia da produtividade, os prejuízos ambientais têm se avolumado com o avanço das fronteiras agrícolas, o uso abusivo de insumos e agrotóxicos, a destruição das florestas, as práticas degradadoras e o uso desordenado das águas que causam, em última análise, armadilhas à exclusão social inerente à busca da eficiência produtiva (da competitividade), qualquer custo, o que exige a recuperação da antiga noção de desenvolvimento social e a propugnação de estratégias e políticas de apoio para grupos sociais e não apenas para o êxito mercantil de agentes individuais (MANIGLIA, 2010, p. 242).

Vê-se claramente, diante de todos esses dados, que a questão do meio ambiente está fortemente atrelada ao consumo, à solidariedade, ao respeito cultural, aos pobres e ao Estado. O problema é que:

[...] os alimentos podem ser produzidos em alta escala e que, mesmo assim, a fome continuará existindo, porque suas causas são outras. Assim, pensar no meio ambiente equilibrado para uma segurança alimentar é buscar um sentido ambiental que evite pobreza e marginalização, que não gere destruição e que não expulse o homem para as periferias das grandes cidades, para lá poluir, passar fome, produzir lixo e viver abandonado pelas políticas públicas (MANIGLIA, 2010, p. 244-5).

Assim, pelo que se entende, a efetivação da segurança alimentar depende também da promoção da justiça ambiental, tendo fortes pontos de contato com esta. Para que ambas justiça ambiental e segurança alimentar - se efetivem, "É preciso fundar uma dinâmica construída no desenvolvimento e na aplicação dos conteúdos de justiça e, em particular, dos direitos humanos fundamentais, firmados numa justiça que exija relação responsável entre o homem e seu meio" (MANIGLIA, 2010, p. 248).

Fica claro, mais uma vez, a natureza holística da segurança alimentar (e do direito humano à alimentação adequada), que depende de uma visão integrada do todo para ser enxergada em sua plenitude, a fim de que se possibilite uma vida melhor. 


\subsection{IMPACTOS À SAÚDE HUMANA}

Há um mito de que somente por meio do consumo de produtos de origem animal o ser humano conseguirá suprir suas necessidades de ferro, cálcio, proteína e outros nutrientes. No entanto, a realidade e as pesquisas começam a demonstrar o contrário. A carne não só é totalmente dispensável como também traz muitos malefícios à saúde humana, tais como doenças cardiovasculares, câncer, diabetes e alergias.

A Comissão das Comunidades Europeias, ao tratar da questão da segurança alimentar e nutricional, traz a questão da saúde humana como sua fonte de maior preocupação. O material produzido por esse ente - chamado "O Livro Branco sobre a Segurança dos Alimentos" descreve forte preocupação com os alimentos de origem de origem animal, pois notadamente estes apresentam maior risco à saúde humana. Em diversos pontos do conteúdo tal assunto é trazido à tona, especialmente no que diz à questão dos aditivos - como remédios, suplementos, vermífugos e antibióticos. Tal assunto tem tanta relevância no continente que já é trazida no preâmbulo do material (que, de outra banda, não se ocupa sequer da questão dos transgênicos ou da nanotecnologia, por exemplo). In verbis: Serão apresentadas propostas relativas ao sector da alimentação animal, com vista a garantir que só sejam utilizados materiais adequados para a sua produção e que a utilização de aditivos seja controlada com maior eficácia (COMISSÃO DAS COMUNIDADES EUROPEIAS, 2010, p. 4).

Ainda sobre esse documento, ressalte-se uma preocupação relevante com o direito de informação dos consumidores. Nesse sentido:

Os consumidores têm o direito de esperar que lhes sejam fornecidas informações úteis e claras sobre a qualidade e os constituintes dos alimentos, por forma a poderem escolher com conhecimento de causa. Assim, serão apresentadas propostas em matéria de rotulagem dos alimentos, baseadas nas regras em vigor. A importância de uma alimentação equilibrada e o seu impacto sobre a saúde serão explicados aos consumidores (COMISSÃO DAS COMUNIDADES EUROPEIAS, 2010, p. 4-5).

Vê-se, já em âmbito preliminar, que a preocupação europeia em termos de segurança alimentar é atinente à questão da saúde, e não à oferta de alimentos - preocupam-se com o que contém nos alimentos, e não se terá alimentos (porque sabem que há). “A aplicação de todas as medidas propostas no Livro Branco permitirá organizar a segurança dos alimentos de forma mais coordenada e integrada, no intuito de atingir o nível de protecção da saúde mais elevado possível” (COMISSÃO DAS COMUNIDADES EUROPEIAS, 2010, p. 5).

Em torno disso, percebe-se que, de acordo com a Comissão, 
o direito à saúde é ameaçado especialmente pelos produtos de origem animal, contundentemente tratados. Prova disso é o fato de o documento criar um sistema de Laboratórios Comunitários de Referência voltadas a fiscalizar somente esses produtos "a fim de prestar apoio analítico especializado à Comissão e aos laboratórios dos Estados-Membros. Esses laboratórios desenvolvem métodos de detecção e prestam assistência aos

laboratórios dos Estados-Membros na aplicação desses métodos" (COMISSÃO DAS COMUNIDADES EUROPEIAS, 2010, p. 13).

Pergunta-se, assim, porque a União Europeia (por meio desse instrumento) se preocupa tanto com os produtos de origem animal? Fica claro que é pelo fato de os mesmos serem naturalmente mais inseguros e aptos a ameaçarem a saúde humana, especialmente ante a cultura de injetar antibióticos e hormônios nos animais. A preocupação se justifica:

A saúde animal constitui [...] um factor importante no âmbito da segurança dos alimentos. Algumas doenças, chamadas zoonoses, como a tuberculose, a salmonelose e a listeriose, podem ser transmitidas aos seres humanos através de alimentos contaminados. Estas doenças podem ser particularmente graves para certas categorias da população. A listeriose pode provocar encefalite e abortos espontâneos. A salmonelose está a transformarse num problema de saúde pública. Dispor de uma panorâmica correcta da situação representa um requisito fundamental para a acção. É consequentemente necessário um controlo comunitário das doenças de origem alimentar e das zoonoses, pelo que importa introduzir exigências harmonizadas em matéria de notificação. (COMISSÃO DAS COMUNIDADES EUROPEIAS, 2010, p. 28).

Afora isso, tem-se ainda outros problemas graves de saúde pública. De acordo com o divulgado pela própria Associação Brasileira de Proteína Animal (ABPA), a "aftosa é o problema principal enfrentado pela suinocultura", e "o setor ainda carrega o fardo da alegação de risco por conta da vacinação de gado". A própria entidade ainda ressalta o risco de uma "peste suína clássica" (ABPA, 2014), demonstrando alguns dos riscos inerentes ao consumo das carnes suína e bovina.

Não bastasse toda essa vulnerabilidade na produção da carne, não se pode esquecer que os riscos à saúde humana têm larga incidência inclusive nos produtos fabricados com o mais alto padrão de qualidade - pelo mero fato de serem de origem animal. Começa-se pelo fato de que o consumo diário de carne processada pode aumentar em $20 \%$ a possibilidade de uma morte precoce (A ENGRENAGEM, 2012).

Ademais, a digestão da carne é notadamente onerosa ao sistema digestivo, têm altos índices de colesterol e grandes impactos sobre o metabolismo. Grandes instituições de nutrição e saúde, dentre as quais a Associação Dietética Americana, Food and Drug Administration 
(FDA), American Heart Association e outras, recomendam as dietas vegetarianas ou veganas como opções necessárias em detrimento da dieta onívora.

Nesse sentido, parece lógico admitir que o consumo de carne reflete negativamente em um aspecto de grande valia no âmbito da segurança alimentar e nutricional, qual seja, a saúde humana, somando-se a isso os outros fatores já ressaltados nos tópicos anteriores a este capítulo.

\section{CONSIDERAÇÕES FINAIS}

O presente trabalho aventou uma série de consequências negativas na produção e consumo de carne (e consequentemente de outros produtos de origem animal). Ainda que de maneira breve e sem exaurir a matéria, fica claro que os impactos decorrentes do onivorismo são amplamente mais prejudiciais do que os hábitos ligados ao vegetarianismo e ao veganismo.

A questão da segurança alimentar, como argumentado, não pode ser vista como a soma de fatores isolados, mas ser encarada como algo muito maior, sob uma perspectiva sistêmica de respeito à vida humana, à vida dos animais e ao Planeta Terra. Para tanto, é necessário atentar aos mais variados aspectos da produção e consumo, prezando não apenas pelo cumprimento das normas jurídicas (que ainda não abarcam a matéria de maneira completa e profunda) mas em observância à ética para com todas as formas de vida.

O direito posto ainda não dá conta de, sob a ótica da segurança alimentar, proteger a vida em sua plenitude. Em que pese a Emenda Constitucional n ${ }^{\circ}$ 64/2010 tenha sido um grande avanço - ao incluir a alimentação no rol dos direitos sociais - tem-se que ainda está longe de se ver efetivado em seus aspectos mais sutis, tal como acesso à alimentação, não obstante os esforços envidados nesse sentido.

O que se argumenta aqui é que a produção e o consumo de carne agem como empecilhos à efetivação da segurança alimentar e nutricional (e consequentemente do direito humano à alimentação adequada) em todos os aspectos, desde os mais superficiais (acesso econômico, por exemplo) aos mais aprofundados e refinados em termos de efeitos (tais como os efeitos diretos e indiretos ao meio ambiente). Não se quer, com isso, referir que a indústria da carne é a única responsável pela mazela da fome, por exemplo, mas apenas apontá-la como um fator impeditivo relevante - que geralmente não é demonstrado.

Para que esse "paradigma onivorista-carnivorista" fosse superado, seria necessário muito mais do que ações estatais, mas um esforço de conscientização dos próprios cidadãos, não obstante o Estado fosse um importante propagador de ações de fomento social e econômico na 
transição para uma alimentação mais saudável (livre de produtos de origem animal). O mero ato de comer traz consigo uma grande responsabilidade social e ambiental, adquirindo também um caráter político.

A agricultura ecológica (e orgânica) aparece, cada vez mais, como um ator de grande importância nesse cenário, ao se revelar como uma importante ferramenta contrahegemônicas das grandes fazendas de animais ou de vegetais como uso de agrotóxicos e organismos geneticamente modificados (OGMs). A agroecologia é um modelo de produção baseado em alicerces ricos que vão além da (importante) conservação ambiental, abrangendo também a segurança alimentar e nutricional e todos os seus demais aspectos. Aplica-se aqui uma série de desdobramentos sociais positivos, inclusive no que tange à melhor distribuição de terras para a prática da agricultura familiar (em detrimento da danosa prática latifundiária).

De qualquer forma, promover um direito humano à alimentação adequada não é tarefa simples, e perpassa por um conjunto integrado e complexo de ações a fim de que se migre para uma efetiva segurança alimentar e nutricional livre das consequências e impactos negativos dos produtos de origem animal - com observância e respeito a todas formas de vida.

\section{REFERÊNCIAS}

A ENGRENAGEM. Produção do Instituto Nina Rosa. Idealização de Paulo Vasconcellos. Roteiro e Direção de Denise Tavares Gonçalves. Com Ellen Jabour e Eduardo Pires. São Paulo: Instituto Nina Rosa, 2012 (16min). Disponível em: <http://www.sejavegano.com.br/>. Acesso em: 01 jul. 2014.

ASSOCIAÇÃO BRASILEIRA DE PROTEÍNA ANIMAL. Aftosa, pedra no sapato da suinocultura. Disponível em: <http://www.abipecs.org.br/news/812/100/Aftosa-pedra-nosapato-da-suinocultura.html>. Acesso em: 08 jul. 2014.

COMISSÃO DAS COMUNIDADES EUROPEIAS. O Livro Branco sobre a Segurança dos Alimentos. Bruxelas: [S.ed.], 2000. Disponível em:

<http://ec.europa.eu/dgs/health_consumer/library/pub/pub06_pt.pdf >. Acesso em: 10 jul. 2014.

GRAFF, Laíse. Os Agrotóxicos e o Meio Ambiente: Uma Abordagem a Partir do Direito Humano à Alimentação Adequada. Caxias do Sul: UCS, 2013. Dissertação (Mestrado em Direito), Programa de Pós-graduação em Direito, Universidade de Caxias do Sul, 2013.

HIRAI, Wanda Griep; ANJOS, Flávia Sacco dos. Estado e segurança alimentar: alcances e limitações de políticas públicas no Brasil. Revista Textos \& Contextos, Porto Alegre, v. 6, n. 2, p. 335-353, jul./dez. 2007.

INSTITUTO DE PESQUISA ECONÔMICA APLICADA (IPEA). Bolsa Família é tema do Panorama Ipea. Disponível em: 
<http://www.ipea.gov.br/portal/index.php?option=com_content\&view=article\&id=20413\&ca tid=255\&Itemid=2>.Acesso em: 08 jul. 2014 .

LUTZENBERGER, José Antonio. Absurdo da agricultura moderna: dos fertilizantes químicos e agrotóxicos à biotecnologia. Outubro de 1998. Disponível em: <http://www.fgaia.org.br/texts/biotec.html>. Acesso em: 09 jul. 2014.

MANIGLIA, Elisabete. As Interfaces do Direito Agrário e dos Direitos Humanos e a Segurança Alimentar. São Paulo: Cultura Acadêmica, 2009. p. 117 e ss.

ORGANIZAÇÃO DAS NAÇÕES UNIDAS PARA A ALIMENTAÇÃO E A AGRICULTURA (FAO). Declaração de Roma Sobre a Segurança Alimentar Mundial e Plano de Acção da Cimeira Mundial da Alimentação. Disponível em:

<http://www.fao.org/docrep/003/w3613p/w3613p00.HTM>. Acesso em: 09 set. 2014.

PIOVEZAN, F. Direitos humanos e o direito constitucional internacional. 7.ed. São Paulo: Saraiva, 2006.

PLANETA SUSTENTÁVEL. Comer carne estimula o desmatamento? Disponível em: <http://planetasustentavel.abril.com.br/noticia/atitude/conteudo_449281.shtml>. Acesso em: 10 jul. 2014.

SCIENTIFICAN AMERICAN BRASIL. Disponível em: <http://www2.uol.com.br/sciam/noticias/efeito_estufa_dos_hamburgueres.html>. Acesso em: 14 jul. 2014.

UOL. Efeitos globais do bife brasileiro. Disponível em:

<http://www2.uol.com.br/sciam/reportagens/efeitos_globais_do_bife_brasileiro.html> Acesso em: 10 jul. 2014. 